\title{
PADRÃO DE INOVAÇÃO TECNOLÓGICA NA INDÚSTRIA DE DEFENSIVOS AGRÍCOLAS BRASILEIRA ${ }^{1,2}$
}

\author{
Eduardo Gonçalves ${ }^{3}$ \\ Mauro Borges Lemos ${ }^{4}$
}

\begin{abstract}
Resumo: Esse artigo explora o padrão de inovação tecnológica da indústria de defensivos agrícolas brasileira. O estudo baseia-se, principalmente, em microdados da Pesquisa de Inovação Tecnológica (PINTEC) e da Pesquisa Industrial Anual de 2005, do Instituto Brasileiro de Geografia e Estatística (IBGE), através das quais as firmas industriais brasileiras foram classificadas em líderes, seguidoras, frágeis e emergentes. Os resultados revelam a existência de firmas líderes, subsidiárias de multinacionais e seguidoras, compostas, em sua maioria, por empresas nacionais, com reduzida capacidade de realização de $\mathrm{P} \& \mathrm{D}$, que focam o mercado de produtos genéricos.
\end{abstract}

Palavras-Chave: Inovação Tecnológica; Defensivos Agrícolas; Política Tecnológica; Brasil.

Abstract: The aim of this paper is to analyze the patterns of technological innovation of the pesticide industry in Brazil in order to suggest industrial policies to reinforce the firm's competitiveness. The database is based on micro-data of the Technological Innovation Survey (PINTEC) and the Yearly Industrial Survey (PIA) of the Brazilian Statistical and Geography Bureau (IBGE) in 2005. Based on this database the Brazilian industrial firms were classified into four categories according to their innovative capacity. The main results show the existence of multinational subsidiaries as technological leaders and follower firms, composed by national firms, which have reduced R\&D capabilities, focusing less technology-intensive products.

Key Words: Technological Innovation; Pesticide Industry; Technological Policies; Brazil.

Recebido em: 01/03/11. Aceito em: 26/05/11.

2 Esse artigo é derivado de projeto de pesquisa intitulado "Determinantes da acumulação de conhecimento para inovação tecnológica nos setores industriais no Brasil: uma avaliação direcionada para formulação de políticas públicas" e financiado pela Agência Brasileira de Desenvolvimento Industrial (ABDI).

3 Prof. Adjunto da Faculdade de Economia da Universidade Federal de Juiz de Fora. E-mail: eduardo.goncalves@ufjf.edu.br.

4 Prof. Titular do Centro de Desenvolvimento e Planejamento Regional da Universidade Federal de Minas Gerais.E-mail: $\underline{\text { mbl@ cedeplar.ufmg.br. }}$ 


\section{Introdução}

A indústria de defensivos agrícolas, como subsetor da indústria química, possui dinamismo tecnológico associado aos avanços científicos da química e, recentemente, da biotecnologia e nanotecnologia, sendo classificada como setor "baseado em ciência" na taxonomia de Pavitt (1984). O surgimento da biotecnologia moderna criou novas oportunidades tecnológicas para o setor de defensivos agrícolas, à medida que as áreas de química e biotecnologia se tornaram única base de conhecimento científico para vários setores, tais como farmacêutico, sementes, alimentos e defensivos agrícolas. O setor de defensivos agrícolas passou a usar a engenharia genética para criação de novas variedades de vegetais, combater pragas e melhorar qualidade dos alimentos (Martins, 2000; Lemos, 1992).

A partir disso, duas consequências são constatadas no setor de defensivos agrícolas: 1) custo crescente de $\mathrm{P} \& \mathrm{D}$, tendo em vista que as atividades agroquímicas pela rota biotecnológica possuem necessidades de gastos de $P \& D$ equivalentes a $25 \%$ do faturamento, enquanto, pela via tradicional, os percentuais são de 10\% (Martinelli Júnior, 2005); 2) redirecionamento de investimentos das líderes mundiais por meio de joint-ventures e acordos cooperativos e aumento do número de fusões e aquisições no setor, com nítidos desdobramentos no mercado brasileiro, principalmente a partir dos anos 90 .

O aumento do número de fusões e aquisições é visto como uma estratégia conduzida pelas empresas líderes mundiais do setor para reduzir riscos e incertezas no mercado de agrotóxicos, pois uma descoberta na área de biotecnologia pode inviabilizar uma linha completa de produtos do setor (Koshiyama e Martins, 2008) ou como alternativa para ampliar economias de escala e escopo em P\&D (Martinelli Júnior e Waquil, 2002). Dessa forma, ao adquirirem firmas com competência na área de biotecnologia, as líderes do segmento de defensivos ampliam sua base tecnológica, diversificam seu processo produtivo, aumentam sua competitividade e ampliam participação no mercado. 
Todas essas transformações tornam relevantes a identificação e a análise da estrutura produtiva de defensivos agrícolas no Brasil, considerado um dos maiores mercados consumidores desses produtos do mundo. Especificamente, procura-se mostrar o número de empresas do setor que possuem liderança tecnológica e de mercado e a natureza de seu capital, nacional ou estrangeiro. Existem firmas nacionais com capacidade de liderança tecnológica ou estas se posicionam de forma passiva no mercado, em termos de estratégias de gastos com inovação e geração de conhecimento necessário para inovar? Se respondidas, tais questões podem orientar a formulação de políticas para fortalecimento de um sistema de inovação setorial.

Este trabalho se assenta sobre a taxonomia de De Negri et al. (2007) e De Negri e Salermo (2005), que organizaram empresas industriais brasileiras em quatro categorias de firmas, segundo sua capacidade de geração endógena de tecnologia, a saber: líderes, seguidoras, emergentes e frágeis. Tal taxonomia foi desenvolvida com os dados da Pesquisa Industrial Anual (PIA) e da Pesquisa de Inovação Tecnológica (PINTEC), ambas do Instituto Brasileiro de Geografia e Estatística (IBGE), especificamente para a PINTEC do período 2003-2005, que possui informações quantitativas para o ano de 2005.

$\mathrm{O}$ artigo possui mais quatro seções. Na segunda, descrevem-se os procedimentos metodológicos para construção da taxonomia adotada. $\mathrm{Na}$ terceira, analisam-se os dados sobre o desempenho produtivo, comercial e o grau de concentração do mercado. Na quarta seção, mostram-se indicadores econômicos e de esforço tecnológico das firmas do setor. A última seção tece considerações finais, associando a dinâmica tecnológica setorial a sugestões de políticas tecnológicas.

\section{Aspectos metodológicos}

Esse trabalho se assenta na classificação das firmas industriais brasileiras de acordo com sua capacidade de liderança associada à sua participação no mercado como inovadora e à sua acumulação de capital (De Negri et al., 2007). 
Com base em Porter (1980), que apresenta três diferentes estratégias de negócios para as empresas (concorrência por diferenciação, por preço e por nichos de mercado), De Negri et al. (2007) se baseiam em dois tipos de liderança: diferenciação de produto e custo. O exercício do primeiro tipo de liderança permite à firma ampliar sua participação no mercado, pois o seu produto é visto como diferente pelo consumidor em relação a diversos atributos, satisfazendo de forma mais apropriada suas necessidades em relação aos produtos concorrentes. No segundo caso, a firma, que apresenta menor custo de produção que os concorrentes, pode induzir o consumidor a adquirir seus produtos, similares aos dos concorrentes, mas vendidos com menores preços.

Outro conjunto de empresas é o das seguidoras, que possuem grande capacidade de acompanhar e imitar as mudanças tecnológicas no seu setor, quer sejam as de diferenciação de produto ou as de redução de custo. Para classificar as firmas industriais brasileiras, os autores utilizaram um conjunto de indicadores principais enunciados a seguir: 1) capacidade de inovar em produto novo para o mercado e exportação com preçoprêmio ${ }^{5}$; 2) capacidade de inovação de processo novo para o mercado e exportação; 3) menor relação custo/faturamento no interior do setor industrial (Grupo CNAE a 3 dígitos); 4) produtividade (valor da transformação industrial por trabalhador) igual ou superior às empresas exportadoras não líderes de seu setor industrial.

Com base nesses indicadores, os autores classificaram as empresas industriais brasileiras em líderes, seguidoras, emergentes e frágeis. Segundo De Negri et al. (2007, p.13-14), as firmas podem ser caracterizadas como se segue ${ }^{6}$.

\footnotetext{
Empresas que obtiveram preço prêmio acima de $30 \%$ nas suas exportações quando comparadas com as demais exportadoras brasileiras do mesmo produto.

6 Procedimentos estatísticos que identificavam se as empresas formavam grupos diferenciados entre si e análise discriminante foram usados para validar a classificação (De Negri et al., 2007).
} 
Empresas Líderes: i) Inovadora de produto novo para o mercado e que exporta com preço prêmio ou ii) Inovadora de processo novo para o mercado, exportadora e de menor (quartil inferior) relação custo/faturamento no seu setor industrial (Grupo CNAE - 3 dígitos);

Empresas Seguidoras: i) demais exportadoras não líderes ou ii) empresas que têm produtividade (valor da transformação industrial por trabalhador) igual ou superior às exportadoras não líderes no seu setor industrial (Grupo CNAE - 3 dígitos);

Empresas Emergentes: empresas não classificadas como líderes e seguidoras, logo, não exportadoras, mas que investem continuamente em $P \& D$ ou inovam produto novo para o mercado mundial ou possuem laboratórios de $\mathrm{P} \& \mathrm{D}$ (departamentos de $P \& D$ e que têm mestres/doutores ocupados em $\mathrm{P} \& D)$.

Empresas Frágeis: demais firmas.

Para realizar tal classificação, foram utilizadas as bases de dados do Instituto Brasileiro de Geografia e Estatística (IBGE), especificamente a Pesquisa sobre Inovação Tecnológica na Indústria Brasileira (PINTEC) do período 2003-2005 e a Pesquisa Industrial Anual (PIA), do período de 1996 a 2006. Ao todo, foram envolvidas mais de 25 mil empresas industriais brasileiras durante o período de 1996 a 2006, representando mais de $95 \%$ do valor adicionado industrial.

Ressalta-se que a classificação das firmas é intrassetorial, pois os indicadores utilizados para classificar as empresas foram calculados dentro do setor. Isso pode explicar a ausência de firmas em algumas categorias da classificação, ou seja, nem todos os setores possuem os quatro tipos de firmas. 
Em relação a outros indicadores, os autores ressaltam que

$$
\begin{aligned}
& \text { no caso do preço prêmio nas exportaçães, o } \\
& \text { procedimento metodológico é por produto } \\
& \text { exportado, nível mais desagregado do que o setor } \\
& \text { da firma; no caso da relação custo/faturamento e } \\
& \text { produtividade (valor da transformação industrial } \\
& \text { por trabalhador), os cálculos são feitos em relação } \\
& \text { ao setor em que a firma opera, considerando setor } \\
& \text { o grupo CNAE (3 dígitos). (DE NEGRI } \text { et al., 2007, } \\
& \text { p. 14) }
\end{aligned}
$$

A partir desses procedimentos metodológicos, o atual artigo analisa diversos indicadores econômicos e de inovação tecnológica para o setor de defensivos agrícolas como um todo ou para a taxonomia de firmas existente no interior desse setor.

\section{Panorama da indústria de defensivos agrícolas no Brasil ${ }^{7}$}

No Brasil, os herbicidas, fungicidas, inseticidas, acaricidas e formicidas são usados principalmente nas culturas de soja, cana-de-açúcar, algodão, milho, café e citros. Somadas, as vendas para essas culturas totalizam $78 \%$ do valor comercializado (Ferreira et al., 2008).

Entre 1996 e 2006, o VBP, em relação ao total da indústria de transformação brasileira, apresentou tendência de crescimento até 1999, atingindo 1,04\% (Tabela 1). Entretanto, tal tendência é interrompida no ano de 2000, retornando a apresentar crescimento após esse ano até 2004, quando o VBP atinge seu maior valor como proporção do total nacional, no período 1996-2006 (1,39\%). Com a crise agrícola de 2005, a trajetória desse indicador retorna a diminuir sua participação no total da indústria de transformação. Em termos absolutos, comparando-se os anos de 2006 e 2004, a queda do VBP equivale a uma perda setorial de $\mathrm{R} \$ 6,2$

\footnotetext{
Nesse artigo, o setor compreende as atividades reunidas no grupo 246 da Classificação Nacional de Atividades Econômicas (CNAE 1.0).
} 
bilhões. Outro indicador, que é a relação entre o valor agregado e o valor bruto da produção, apresenta comportamento ainda pior, tendo em vista que recua de 0,40 em 1999, valor máximo do período 1996-2006, para $0,33 \mathrm{em} 2006$. Nota-se que tal valor se situa num patamar inferior ao do ano de $1996(0,38)$. Os diferentes indicadores mostram a diminuição do valor da produção e da participação do valor bruto de produção em relação à indústria de transformação, especialmente no período 2004-2006, além da redução de agregação de valor pelas empresas de defensivos agrícolas localizadas no Brasil.

Tabela 1 - Valor Bruto da Produção e da Transformação Industrial na Indústria de Defensivos Agrícolas. Período: 1996-2006 (em $\mathrm{R}$ \$ bilhões).

\begin{tabular}{ccccc}
\hline Ano & VBP & VTI & VTI/VBP & $\begin{array}{c}\text { \% VBP } \\
\text { nacional }\end{array}$ \\
\hline 1996 & 7,1 & 2,7 & 0,38 & 0,68 \\
1997 & 8,1 & 3,0 & 0,37 & 0,76 \\
1998 & 9,5 & 3,2 & 0,33 & 0,92 \\
1999 & 11,0 & 4,5 & 0,40 & 1,04 \\
2000 & 9,0 & 3,3 & 0,37 & 0,81 \\
2001 & 11,2 & 3,6 & 0,32 & 0,98 \\
2002 & 10,3 & 4,0 & 0,39 & 0,91 \\
2003 & 12,7 & 4,7 & 0,37 & 1,15 \\
2004 & 16,7 & 6,2 & 0,37 & 1,39 \\
2005 & 11,1 & 3,9 & 0,35 & 0,93 \\
2006 & 10,5 & 3,5 & 0,33 & 0,83 \\
\hline
\end{tabular}

Fonte: SIDRA-IBGE, PIA. Deflacionados pelo IPA-OG.

A trajetória das importações de defensivos agrícolas apresenta forte aumento a partir de 2002 até 2004 (Gráfico 1). Em 2002, as importações totalizavam US\$ 496 milhões, ao passo que, até 2004, houve 126\% de aumento, atingindo a cifra de US\$ 1,1 bilhão. Esse desempenho das importações pode ser explicado pelo comportamento da taxa de câmbio, 
pois coincide com a fase de contínua apreciação da moeda nacional frente ao dólar. Outro argumento que explica a evolução das importações até 2006 é a magnitude e o destino dos investimentos realizados no Brasil pelas empresas do setor.

Segundo Terra (2008), observa-se que os investimentos realizados em 2006 e 2007 representaram apenas $22 \%$ do total de 2001 e se destinaram à modernização das plantas produtivas, ao invés da ampliação da capacidade produtiva. Dessa forma, as necessidades crescentes da agricultura brasileira foram atendidas pela produção externa. $\mathrm{O}$ ano de 2004 também marca reversão da tendência de aumento das importações, que caem $88 \%$ até 2007 . Isso se explica por causa da crise do agronegócio brasileiro, em particular das culturas de soja, algodão, arroz, feijão e trigo. Por outro lado, algumas culturas continuaram a consumir mais defensivos em relação aos anos anteriores, como cana-de-açúcar, café, batata inglesa, citros, tomate envarado, fumo e maçã, por causa do aquecimento da demanda interna ou de preços internacionais em alta (Ferreira e Vegro, 2008).

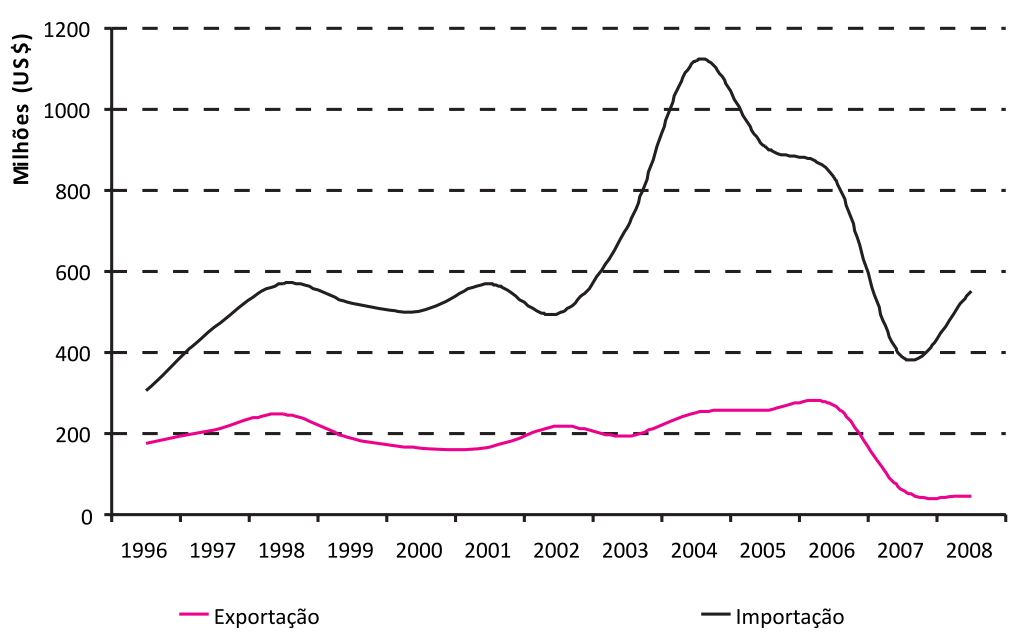

Gráfico 1: Exportações e Importações de Defensivos Agrícolas.

Período: 1996-2008. (em US\$ milhões)

Fonte: Elaboração própria a partir de dados da Secex/MDIC. 
Nota-se que a queda das importações de defensivos se acentua ao longo de todos os meses de 2006 até 2007, o que se explica pelo endividamento dos produtores rurais que diminuíram as compras de defensivos. Estimativas apontam que a dívida agrícola aumentou de 35,3\% do PIB agrícola, em 1999, para 54,8\%, em 2006 (IICA, 2007, p. 67). As dívidas foram contraídas no período de aquecimento do agronegócio (2002-2005) e aumentaram com a queda dos preços agrícolas a partir de 2006. Por outro lado, as exportações de defensivos agrícolas apresentaram crescimento de 53\%, no período 1996-2006. A trajetória de crescimento foi interrompida pela crise financeira internacional, que afetou as vendas externas dos anos de 2007 e 2008.

Há indícios, porém, de que as exportações têm se concentrado em produtos ou ingredientes de menor valor agregado e com menor densidade tecnológica. A Tabela 2 mostra o indicador valor/peso (US\$ FOB/kg) dos produtos exportados e importados. No caso das exportações, tal indicador sofre redução ao longo do período, passando de $6,65 \mathrm{US} \$ / \mathrm{kg}$ em 1996 para 3,84 US\$/kg em 2008. 
Tabela 2 - Valor Médio das Exportações e Importações de Defensivos Agrícolas. Período: 1996-2008 (em US\$ FOB / kg)

\begin{tabular}{lcc}
\hline Ano & Importação & Exportação \\
\hline $\mathbf{1 9 9 6}$ & 7,36 & 6,65 \\
$\mathbf{1 9 9 7}$ & 7,71 & 6,58 \\
$\mathbf{1 9 9 8}$ & 7,91 & 7,10 \\
$\mathbf{1 9 9 9}$ & 7,50 & 5,92 \\
$\mathbf{2 0 0 0}$ & 6,80 & 5,45 \\
$\mathbf{2 0 0 1}$ & 6,13 & 5,37 \\
$\mathbf{2 0 0 2}$ & 5,85 & 5,63 \\
$\mathbf{2 0 0 3}$ & 6,16 & 4,90 \\
$\mathbf{2 0 0 4}$ & 6,63 & 4,99 \\
$\mathbf{2 0 0 5}$ & 7,24 & 5,32 \\
$\mathbf{2 0 0 6}$ & 6,71 & 5,31 \\
\hline $\mathbf{2 0 0 7}$ & 7,18 & 5,21 \\
\hline $\mathbf{2 0 0 8}$ & 7,51 & 3,84 \\
\hline
\end{tabular}

Fonte: Elaboração própria a partir de dados da Secex/MDIC.

Ao mesmo tempo, as importações de ingredientes ou de produtos de alto valor agregado para fabricação de defensivos no Brasil mostram duas fases distintas. Na primeira, houve tendência decrescente até 2002, quando o indicador diminui de 7,36 US\$ $/ \mathrm{kg}$ para $5,85 \mathrm{US} \$ / \mathrm{kg}$. Na segunda fase, porém, o indicador retoma tendência de crescimento, atingindo 7,51 $\mathrm{US} \$ / \mathrm{Kg}$. O aumento do valor agregado médio dos produtos importados reflete dependência tecnológica crescente do Brasil no setor.

O número de empresas do setor mostra redução de $11,54 \%$ no período de 1996-2000 e aumento de 12,17\% no período 2000-2005. Esse crescimento, porém, não foi capaz de produzir uma taxa positiva de aumento do número de empresas para o período 1996-2005 (Tabela 3). 
O desempenho até 2005 pode ser explicado pelas tendências mundiais do setor que o tornaram mais concentrado, reduzindo especialmente o número microempresas (até 49 empregados) e aumentando os estratos de 250 a 499 empregados e os das grandes empresas (de 500 a 999 empregados). O número de fabricantes é modesto se considerada a evidência de que o mercado brasileiro é o maior do mundo, estimado em US\$ 7,1 bilhões em 2008, o que supera o consumo do mercado norteamericano, equivalente a US\$ 6,6 bilhões, segundo a Associação Nacional de Defesa de Vegetal (ANDEF).

Tabela 3 - Número de Empresas na Indústria de Defensivos Agrícolas em 1996, 2000 e 2005

\begin{tabular}{l|ccc|ccc}
\hline & \multicolumn{3}{|c|}{ Número de empresas } & \multicolumn{3}{|c}{ Taxa de crescimento (\%) } \\
Pessoal ocupado & 1996 & 2000 & 2005 & $96 / 00$ & $00 / 05$ & $96 / 05$ \\
\hline ATÉ 49 & 106 & 88 & 96 & $-16,98$ & 9,09 & $-9,43$ \\
DE 50 A 99 & 10 & 11 & 12 & 10,00 & 9,09 & 20,00 \\
DE 100 A 249 & 11 & 11 & 13 & 0,00 & 18,18 & 18,18 \\
DE 250 A 499 & 3 & 5 & 6 & 66,67 & 20,00 & 100,00 \\
DE 500 A 999 & 0 & 0 & 2 & - & - & - \\
1000 OU MAIS & 0 & 0 & 0 & - & - & - \\
Total & 130 & 115 & 129 & $-11,54$ & 12,17 & $-0,77$ \\
\hline
\end{tabular}

Fonte: RAIS/MTE.

Coerentemente com os dados acima, a evolução dos indicadores de participação do mercado das quatro (CR4) e oito maiores empresas (CR8) evidencia que o segmento industrial de defensivos agrícolas é concentrado, além de ter havido um aumento da concentração ao longo do período analisado (Gráfico 2). Em relação a 1996, os indicadores CR4 e CR8 variaram de $51 \%$ para $61 \%$ e de $71 \%$ para $84 \%$, respectivamente. A indústria de defensivos agrícolas pode ser caracterizada como oligopólio diferenciado, em que um número reduzido de subsidiárias de multinacionais lidera econômica e tecnologicamente o mercado. O padrão de competição está baseado na diferenciação de 
produto vertical, que é realizada com intensa atividade de inovação tecnológica, como nos setores baseados em ciência (Lemos, 1992).

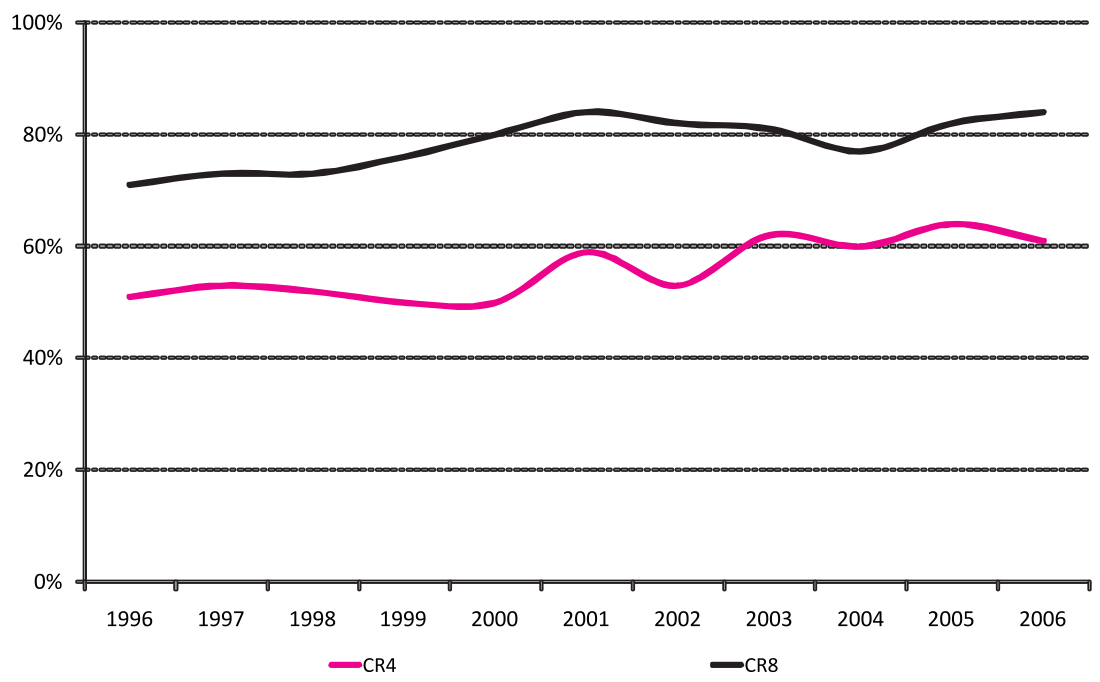

Gráfico 2: Participação de Mercado de Empresas de Defensivos Agrícolas (19962006)

Fonte: Elaboração própria a partir da PIA/IBGE.

Segundo Koshiyama e Martins (2008) e Velasco e Capanema (2006), a configuração atual do setor ilustra várias operações de fusão e aquisição, tanto intrassetorial quanto intersetorial. Nos primeiros casos, foram criadas grandes corporações como Syngenta e Dow AgroSciences. No segundo caso, empresas de sementes, de biotecnologia, do segmento de cana-deaçúcar e até algodão foram adquiridas, caso da Dow AgroSciences ( FT Biogenética, Empresa Brasileira de Sementes etc.), Monsanto ( Sementes Agroceres, FT Pesquisas e Sementes, Agroeste, Alellyx, CanaVialis, grupo Maeda etc.) e DuPont ( aquisição de $80 \%$ da Pioneer Hi-Bread International e 50\% da Merck, formando a DuPont Merck Pharmaceutical). 
No Brasil, as fusões e aquisições contribuíram para aumentar o grau de desnacionalização das firmas do setor, tendo em vista que, das quatro maiores empresas nacionais, três foram adquiridas por empresas multinacionais ao longo dos anos 90, conforme Koshiyama e Martins (2008). Como as empresas líderes do mercado brasileiro são subsidiárias de multinacionais, o Brasil não tem papel de destaque na divisão internacional do trabalho em $\mathrm{P} \& \mathrm{D}$, que envolve primordialmente pesquisa básica. As novas moléculas químicas são descobertas nos laboratórios de P\&D das matrizes das grandes empresas mundiais, como Syngenta, Monsanto, Dupont e FMC. As unidades brasileiras realizam atividade de P\&D em torno da molécula já descoberta para fins de criação de soluções e formulações para fins específicos e novas misturas. ${ }^{8}$

As barreiras à entrada no setor não estão vinculadas à existência de grandes economias de escala, ${ }^{9}$ pois estas são modestas em relação aos outros segmentos da indústria química, mas sim a outras três características do setor (Velasco e Capanema, 2006; Martinelli Júnior e Waquil, 2002; Koshiyama e Martins, 2008).

Primeiro, é crescente o conteúdo científico da P\&D do setor, em razão da convergência da base de conhecimento dos setores farmacêutico, de sementes, de alimentos, de agrotóxicos e de biotecnologia, o que tem claros rebatimentos sobre o aumento do custo de realizar P\&D. A convergência da base de conhecimento representa a possibilidade de comandar o ritmo e direção das inovações, tendo em vista a sua influência sobre o grau de obsolescência tecnológica dos produtos existentes. Além disso, os investimentos em biotecnologia para produção de sementes transgênicas, adaptadas às marcas de seus efensivos agrícolas, permitem a venda de pacotes inteiros de produtos aos agricultores, que vão desde a semente manipulada geneticamente ao pesticida. ${ }^{10}$

\footnotetext{
Martinelli e Waquil (2002) mencionam a unidade brasileira da DuPont como exceção, por causa da existência de um laboratório no País para descoberta de moléculas.

9 Frenkel e Silveira (1996) justificam esse argumento a partir da característica do processo produtivo, que ocorre através de bateladas e não de forma contínua.

10 Além disso, a empresa pode impor aumentos de preços aos agricultores, como ilustra o caso da Monsanto, que aumentou recentemente em $26 \%$ os royalties cobrados por suas sementes de soja modificadas geneticamente e tolerantes ao herbicida Roundup em Mato Grosso. Disponível em: http://www.valoronline.com.br/ V a 1 or I m p resso/M a teri a I m p r e s s o a s p x ? d t m a t e r i a $=21-8$ $2009 \&$ codmateria $=5775595 \&$ codcategoria $=83 \&$ tp $=12 \&$ search Term $=$ monsanto.
} 
Segundo, a produção de defensivos exige a construção de redes de distribuição e de assistência técnica aos usuários. Conforme Velasco e Capanema (2006), o custo de distribuição é alto por causa do portfólio reduzido de produtos. No caso de empresas especializadas em produtos genéricos, em geral não patenteados, há dificuldade em criar fidelidade do consumidor em relação à sua marca comercial.

Terceiro, o setor possui procedimentos legais e de registros de produtos burocráticos e custosos em termos de tempo, ainda que modificações no marco legal tenham sido buscadas na década de 2000. Nesse sentido, podem ser citadas modificações, ocorridas entre 2002 e 2006, visando à simplificação do registro e à redução do seu custo, vistas como prováveis redutoras das barreiras à entrada, que se tornaram maiores após a promulgação da Lei 7.802 de 1989 (Lei dos Agrotóxicos).

Antes dos decretos desses anos, o sistema de registro dos defensivos com patentes vencidas era baseado no recolhimento de referências bibliográficas disponíveis na literatura internacional sobre testes de toxicidade crônica dos produtos. O sistema de registro por equivalência realizava a comparação de características físico-químicas entre o produto pleiteante para registro e aquele já registrado. Isso representa decréscimo do número de estudos necessários, do custo e do tempo para consecução do registro.

Entretanto, as empresas líderes também foram beneficiadas pela nova sistemática de registro, possibilitando-lhes maiores economias de escala e escopo. Segundo Terra (2008), não existe até o momento evidências de que tais mudanças no marco legal tenham sido efetivas no sentido de diminuir a concentração de mercado, ainda que os primeiros registros por equivalência tenham sido efetuados com atraso em relação às datas dos decretos por causa de ações judiciais conduzidas pelas empresas detentoras dos dados dos produtos de referência. De fato, os dados mostrados no Gráfico 4 indicam, ao contrário, crescente concentração de mercado. 
Mesmo assim, analisando dados disponibilizados pela Associação Brasileira dos Defensivos Genéricos (AENDA), ${ }^{11}$ é possível verificar que, enquanto a evolução do número total de ingredientes ativos no período 2005-2008 foi de 4,6\%, o número de ofertantes de produtos agroquímicos com determinado ingrediente ativo aumentou, mostrando maior concorrência no setor, em razão da mudança no marco legal. Houve aumento de $31 \%$ do número de ingredientes ativos por três ou mais empresas, enquanto os ingredientes ofertados por uma só empresa cresceram apenas 2,7\% no período 2005-2008. No entanto, o número de ingredientes ativos ofertados por uma só empresa ainda representa $73 \%$ do total dos ingredientes em 2008 contra $11 \%$ e $16 \%$ de ingredientes oferecidos por duas e três ou mais empresas, respectivamente. Ainda que os efeitos desejados de redução da concentração de mercado não tenham ocorrido ainda, porque as próprias líderes de mercado podem se beneficiar da nova sistemática de registro de produtos e não somente as pequenas e médias empresas, a mudança no marco legal foi bem-vinda e pode sinalizar maior concorrência no longo prazo.

$\mathrm{O}$ indicador de primazia ${ }^{12}$ entre as quatro e as oito maiores empresas do setor apresenta decréscimo de 35\% para 30\% entre 1996 e 2001, com tendência de aumento deste valor até 42\% em 2005 (Gráfico 3). Entretanto, a participação de mercado da maior empresa, em relação às quatro maiores, retorna para o valor de $35 \%$ em 2006. A primazia entre as oito maiores segue padrão similar, situando-se entre os limites de $25 \%$ e $20 \%$ em todo o período. Isso sinaliza que existe acirrada disputa de mercado entre as líderes de mercado do setor, impedindo que a participação da principal empresa cresça constantemente. De fato, existem algumas evidências de alternância da posição de liderança no mercado brasileiro. Com base em Velasco e Capanema (2006) e Fermam

${ }_{11}$ Disponível em: http://www.aenda.org.br/new_defensivos.htm.

12 Indicador de primazia: participação da maior empresa no mercado dividido pela participação das $4(\operatorname{Pr} 4)$ ou, alternativamente, 8 (Pr8) maiores empresas na CNAE. Formalmente, o indicador pode ser definido como

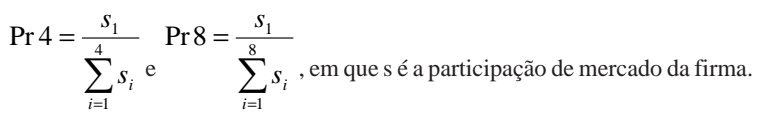


(2008), foram comparados os anos de 2005 e 2002. A Bayer CropScience e a Syngenta, respectivamente, com $18,8 \%$ e $15,4 \%$ de participação de mercado, alternaram de posição no período (Syngenta com 17,2\% e Bayer CropScience com 14\%), enquanto Basf e Monsanto mantiveram suas posições de terceira e quarta maiores empresas no mercado brasileiro. As subsidiárias de multinacionais que dominam o mercado brasileiro têm vantagens competitivas associadas ao comércio intrafirma, pois têm oferta garantida de matéria-prima e produtos intermediários e acesso direto a um fluxo contínuo de inovações por parte das matrizes.

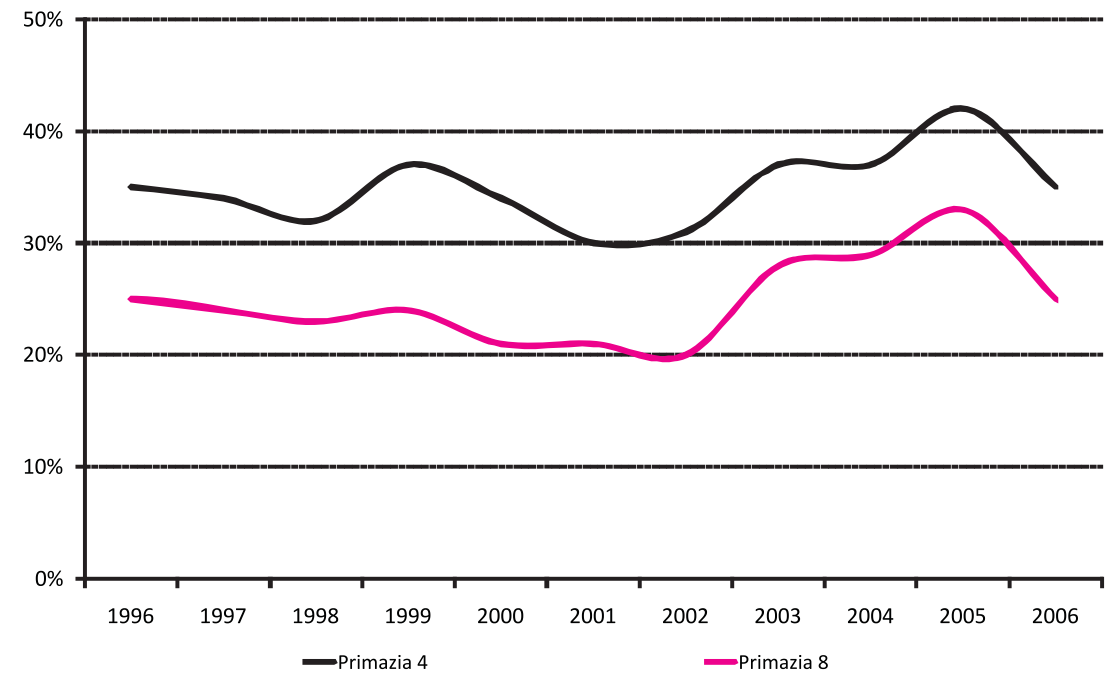

Gráfico 3: Indicador de Primazia da Indústria de Defensivos Agrícolas (1996-2006)

Fonte: Elaboração própria a partir da PIA/IBGE.

Em grande medida, as transformações descritas nessa seção reforçam a natureza de oligopólio diferenciado do setor de defensivos agrícolas, como caracterizado por Possas (1985). Segundo o autor, tal estrutura de mercado é marcada por elevadas barreiras à entrada, alto grau de concentração da produção e formas de competição via diferenciação de produtos. No caso do setor de defensivos agrícolas, muitas das barreiras 
à entrada são erigidas em função da capacidade tecnológica e de investimento das empresas líderes, cujos investimentos em P\&D são capazes de produzir novas moléculas químicas que geram efeitos tóxicos seletivos (Terra, 2008). O padrão recente de inovação tecnológica do setor será analisado na seção a seguir.

\section{Padrão de Inovação Tecnológica do Setor de Defensivos Agrícolas no Brasil}

\subsection{Indicadores econômicos segundo a taxonomia líder-seguidoras tecnológicas}

As Tabelas 4 e 5 permitem analisar as diferenças entre as líderes e seguidoras, com base em diferentes indicadores. ${ }^{13}$ As líderes constituem $16 \%$ do número total de empresas, sendo responsáveis por $77 \%$ do faturamento, $68,5 \%$ dos lucros totais, $78 \%$ da massa salarial total, $69 \%$ dos investimentos, $61 \%$ das exportações e $60,5 \%$ do pessoal ocupado. Todos esses indicadores confirmam que um número reduzido de empresas domina a maior parte do mercado de defensivos agrícolas no Brasil. Essas empresas dominam os dois conjuntos possíveis de produtos do mercado: patenteáveis, frutos de esforços de $\mathrm{P} \& \mathrm{D}$ e criadores de lucros extraordinários e genéricos (equivalentes), que apenas precisam de registro nos órgãos públicos para efetuar sua produção, tendo em vista que suas patentes já expiraram.

\footnotetext{
${ }^{13} \mathrm{Na}$ indústria de defensivos agrícolas, não foram identificadas, pelos critérios descritos na seção 2, empresas frágeis ou emergentes.
} 
Tabela 4 - Porte das Firmas Líderes e Seguidoras na Indústria de Defensivos Agrícolas (2005)

\begin{tabular}{ll|cc}
\hline \multicolumn{2}{l|}{ Indicador } & Líderes & Seguidoras \\
\hline \multicolumn{2}{l|}{$\begin{array}{l}\text { Número de empresas } \\
\text { Pessoal Ocupado } \\
\text { (número de pessoas) }\end{array}$} & 7 & 36 \\
\hline $\begin{array}{l}\text { Salários Totais } \\
\text { Faturamento }\end{array}$ & (R\$ milhões) & 5229,39 & 5372,98 \\
\hline Lucros Totais & (R milhões) & 9707,3 & 151,3 \\
\hline $\begin{array}{l}\text { Investimento Total } \\
\text { Expones) }\end{array}$ & (R\$ milhões) & 344,7 & 158,3 \\
\hline
\end{tabular}

Fonte: Elaboração própria a partir da PIA e PINTEC/IBGE.

Tabela 5 - Indicadores da Indústria de Defensivos Agrícolas para Líderes e Seguidoras (2005)

\begin{tabular}{l|cc}
\hline Indicador & Líderes & Seguidoras \\
\hline Número de empresas & 7 & 36 \\
Salário médio (R\$) & 5356,3 & 2347,0 \\
\hline Salário médio no pessoal industrial (R\$) & 4453,9 & 2378,5 \\
Faturamento médio (R\$ milhões) & 1386,8 & 81,8 \\
\hline Lucro/Custo (\%) & 3,5 & 3,3 \\
VTI/Faturamento (\%) & 24,3 & 32,1 \\
Exportações/Faturamento (\%) & 3,3 & 4,9 \\
Importações/Custos (\%) & 31,4 & 20,5 \\
\hline Investimento/Faturamento (\%) & 1,8 & 3,7 \\
Gasto P\&D/Faturamento (\%) & 0,6 & 0,3 \\
\hline
\end{tabular}

Fonte: Elaboração própria a partir da PIA e PINTEC/IBGE. 
Informações de Frenkel e Silveira (1996) revelam que as líderes atuam também nos mercados de produtos equivalentes que permitem ganhos de economias de escala e venda de matérias-primas básicas (ingredientes ativos) para outros produtores de defensivos agrícolas. Em 2008, o mercado de produtos equivalentes era estimado em $70 \%$ do valor global do mercado de defensivos. ${ }^{14}$ As seguidoras, em sua maioria, exploram o mercado de produtos genéricos, tendo em vista o não envolvimento com inovação e ausência de esforço relevante em P\&D por grande parte delas.

A disparidade em relação ao tamanho de firmas nas categorias de líderes e seguidoras é muito evidente. Enquanto as líderes faturam, aproximadamente, R \$ 1,4 bilhão por firma, as seguidoras, em média, faturam R\$ 81 milhões. Indicadores de pessoal ocupado por empresa também sinalizam tais diferenças de tamanho, tendo em vista que as líderes e as seguidoras possuem, em média, 1.175 e 149 empregados. O tamanho maior das primeiras explica a capacidade de suportar os custos fixos elevados de P\&D. As diferenças constatadas se refletem na remuneração média percebida pelos empregados, não somente do quadro administrativo, mas também do "chão de fábrica". Comparando-se salários médios nas duas categorias, nota-se que nas líderes o salário médio é $128 \%$ maior num caso e $87 \%$ no outro.

Há também uma tendência de as líderes agregarem menos valor à atividade produtiva, pois o indicador VTI/Faturamento delas é de $24 \%$, ao passo que nas seguidoras o indicador é de $32 \%$. Essa diferença deve refletir o comércio intragrupo das líderes, considerando que são filiais de multinacionais que mantêm intercâmbio com suas matrizes no exterior. Coerente com esse argumento é o indicador que mostra a relação entre importações e custos que, no caso das líderes e seguidoras, é 30,4\% e $20,5 \%$, respectivamente. Essa evidência corrobora a tendência de

${ }^{14}$ http://www.coplana.com/gxpfiles/ws001/design/RevistaCoplana/2008/Outubro/pag18-19.pdf. 
crescimento do valor agregado médio das importações, constatada anteriormente, sinalizando que as líderes tecnológicas são responsáveis pelas importações de insumos e princípios ativos de complexa sofisticação tecnológica.

\subsection{Indicadores de inovação tecnológica no setor ${ }^{15}$}

Segundo dados da pesquisa, todas as líderes tecnológicas são inovadoras de produto e investem em $\mathrm{P} \& \mathrm{D}$. Ampla maioria (86\%) inova em processo. Nas seguidoras, apenas $33 \%$ das firmas inovam, sendo a frequência de inovadores de produto e processo de, respectivamente, $22 \%$ e $25 \%$. Em relação ao investimento em $\mathrm{P} \& \mathrm{D}$, apenas um terço o realiza.

Como a dinâmica inovadora do setor de defensivos agrícolas está tradicionalmente vinculada à área de conhecimento da química, inovações de produto no setor só podem ser geradas se novas moléculas químicas forem descobertas. Nesse caso, o regime de apropriação garante a exploração de lucros de natureza schumpeterianos porque novas moléculas são patenteáveis. Isso segmenta o mercado de produtos finais em dois: o de produtos patenteados e o de produtos genéricos, cuja proteção já expirou e a produção depende apenas de registro em órgão público.

A base tecnológica vinculada à química apresenta tendências de sinergias verticais e horizontais para atividades de $\mathrm{P} \& \mathrm{D}$, o que leva uma firma a conquistar competência específica na área de química fina. Logo, uma trajetória natural é a diversificação da firma na cadeia química por meio de integração horizontal e vertical. A especialização de uma firma numa "árvore genealógica" de grupos químicos básicos gera toda uma trajetória específica de inovações. A especificidade do conhecimento da firma em química final aumenta o grau de apropriação dos retornos da inovação e constrói barreiras à entrada, especialmente a proteção por patentes. As características técnicas do setor abrem uma trajetória natural para

\footnotetext{
15 As definições usadas pelo IBGE para inovações de produto, processo e indicadores de esforço tecnológico usados na Tabela 6 podem ser consultados no sítio do instituto. Disponível em http://www.pintec.ibge.gov.br/ downloads/InstrucoesPINTEC2008.pdf
} 
inovações incrementais garantidas pela obsolescência de produtos existentes, tendo em vista a resistência desenvolvida pelas pragas e suas reações reprodutivas aos efeitos letais dos pesticidas, pela demanda de novos produtos (Lemos, 1992).

Ressalta-se que o lançamento de novos produtos não é muito frequente no setor porque é preciso longo tempo para avaliar testes nas plantações e esperar licenças junto aos órgãos públicos. Em média, estima-se que, da descoberta da molécula até o lançamento do produto, são necessários sete anos de P\&D (Martinelli Júnior, 2005). Além disso, o setor passa por amadurecimento tecnológico (Hartnell, 1996), tendo em vista que é crescente a dificuldade para descoberta de novos ingredientes ativos. Isso contribui ainda mais para alargar o ciclo de inovações do setor. Dessa forma, o desenvolvimento de inovações incrementais de novas formulações, a partir de uma molécula base, é mais atraente, proporcionando maior rapidez de retorno e ganhos de escopo. Em consequência da dificuldade de introdução de inovações no setor, houve aumento da importância econômica do segmento de mercado de produtos genéricos, que passou a ser estratégico economicamente não somente por empresas seguidoras e de menor estrutura econômica e tecnológica, mas também pelas líderes. Por causa disso, as empresas líderes do setor adquiriram empresas de genéricos a fim de estender o prazo de recuperação de investimentos dos produtos cujas patentes já expiraram.

A intensidade de P\&D da indústria de defensivos agrícolas no Brasil, medida pela proporção dos gastos de $\mathrm{P} \& \mathrm{D}$ em relação ao faturamento, é de $0,43 \%$, estando abaixo da média da indústria de transformação $(0,66 \%)$. Ainda que o padrão mundial de inovações no setor, se considerada a rota biotecnológica e nanotecnológica ${ }^{16}$ seguida pelas líderes do setor no mundo, seja intensivo em esforço interno de $\mathrm{P} \& \mathrm{D}$ e marcado por alta

\footnotetext{
${ }^{16}$ Há evidências de que grandes corporações, como Basf e Bayer, desenvolvem pesquisas sobre a formulação de pesticidas em nanoescala, enquanto a Syngenta comercializa defensivos agrícolas formulados como microemulsões (Dulley, 2004). Os investimentos dessas empresas na nanotecnologia sugerem fusão dessa área de conhecimento com a biotecnologia, antecipando diversas aplicações para a agricultura, como: 1) otimização da eficácia das partículas de pesticidas pela nanoencapsulação; 2) programação das cápsulas para liberação do princípio ativo sob diferentes condições; 3) redução de danos às culturas; e 4) diminuir a perda de pesticidas por evaporação.
} 
oportunidade tecnológica e cumulatividade, isso não se reproduz no Brasil e reforça a tese de que as multinacionais realizam tais gastos em suas matrizes no exterior, relegando às subsidiárias instaladas no Brasil funções menos intensivas em P\&D.

Se for considerada a distribuição dos gastos totais das líderes, verificase que a participação dos gastos internos com P\&D é de $33 \%$. As participações dos três principais gastos cujo conhecimento é de natureza mais intangível (P\&D interno, compra de P\&D e aquisição de outros conhecimentos externos) totalizam $42,6 \%$ dos recursos, ao passo que os gastos exclusivos com conhecimento de natureza tangível, incorporado em máquinas e equipamentos, situam-se em torno de 13\% (Tabela 6).

Tabela 6 - Distribuição Percentual dos Gastos em Atividades Inovativas da Indústria de Defensivos Agrícolas, por categoria de empresa (2005)

\begin{tabular}{l|ccc}
\hline \multirow{2}{*}{ Indicador } & \multicolumn{3}{|c}{ Tipo de empresa } \\
\cline { 2 - 4 } & Líderes & Seguidoras & Total \\
\hline Número de empresas & 7 & 36 & 43 \\
Gastos em atividades inovativas & 141,4 & 76,6 & 218,0 \\
(em milhões de R\$) & $(100 \%)$ & $(100 \%)$ & $(100 \%)$ \\
Gastos em P\&D interno & 47,0 & 7,8 & 54,8 \\
(em milhões de R\$) & $(33,2 \%)$ & $(10,2 \%)$ & $(25,2 \%)$ \\
Gastos em P\&D externo & 8,7 & 0,1 & 8,8 \\
(em milhões de R\$) & $(6,2 \%)$ & $(0,1 \%)$ & $(4,0 \%)$ \\
Aquisição de outros conhecimentos & 4,5 & 21,7 & 26,2 \\
(em milhões de R\$) & $(3,2 \%)$ & $(28,3 \%)$ & $(12,0 \%)$ \\
Aquisição de máquinas e equipamentos & 18,6 & 23,4 & 42,0 \\
(em milhões de R\$) & $(13,1 \%)$ & $(30,5 \%)$ & $(19,3 \%)$ \\
Treinamentos & 10,0 & 0,3 & 10,3 \\
(em milhões de R\$) & $(7,1 \%)$ & $(0,4 \%)$ & $(4,7 \%)$ \\
Gasto em introdução das inovações & 32,5 & 2,3 & 34,8 \\
(em milhões de R\$) & $(23,0 \%)$ & $(3,0 \%)$ & $(15,9 \%)$ \\
Projeto industrial & 20,0 & 21,0 & 41,1 \\
(em milhões de R\$) & $(14,2 \%)$ & $(27,5 \%)$ & $(18,9 \%)$ \\
\hline
\end{tabular}

Fonte: Elaboração própria a partir da PIA e PINTEC/IBGE. 
As seguidoras, porém, seguem padrão diferente das líderes, pois concentram a maior parte dos gastos de inovação com aquisição de máquinas e equipamentos $(30,5 \%)$, com outros conhecimentos externos $(28,3 \%)$ e com projeto industrial $(27,5 \%)$. Nota-se que os gastos com P\&D interno constituem apenas $10 \%$ do total de recursos alocados para inovação. Esse padrão se justifica por causa da atuação nos segmentos de mercado em que os produtos são genéricos, de patentes expiradas, ou em que é preciso produzir sob licenciamento, com consequente pagamento de royalties, como se atesta pela elevada proporção de recursos gastos, acima destacados, com outros conhecimentos externos. As maiores empresas de capital nacional que operam no segmento de genéricos são: Nortox (Arapongas - PR), Produquímica (Curitiba - PR), Iharabras S.A. Indústrias Químicas (Sorocaba - SP), Sipcam Isagro Brasil S.A. (Uberaba - MG), Buschle \& Lepper (Joinville - SC) e Agro Química Maringá S.A. (Diadema -SP).

Dados dessa pesquisa mostram que os investimentos totais e os gastos em P\&D concentram-se nas empresas líderes tecnológicas, especialmente os últimos que totalizam $88 \%$ dos gastos. Com base nos indicadores de intensidade de investimento e P\&D (Tabela 5), as líderes se destacam mais do que as seguidoras em relação à intensidade de P\&D, com $0,6 \%$ contra $0,3 \%$, ao passo que as seguidoras são mais intensivas em investimentos tangíveis, com $3,7 \%$ contra $1,8 \%$, o que reflete o envolvimento maior destas com conhecimento incorporado em máquinas e equipamentos.

\section{Considerações Finais}

O processo de acumulação de conhecimento da indústria de defensivos agrícolas mundial apresenta alto nível de oportunidades tecnológicas e de apropriação, tendo em vista as possibilidades abertas pela biotecnologia em firmas que já possuíam competência específica na área de química fina. Em termos de liderança tecnológica, o mercado brasileiro de agroquímicos é dominado por sete empresas e 36 seguidoras. As líderes 
são filiais de grandes corporações internacionais que competem no segmento de produtos de alto valor agregado, resultantes de intensos investimentos em P\&D de suas matrizes, com retornos da inovação apropriados por patentes. As seguidoras são compostas, em sua maioria, por empresas nacionais, com reduzida capacidade de realização de $\mathrm{P} \& \mathrm{D}$, que focam o mercado de produtos genéricos.

As líderes tecnológicas são muito intensivas em conhecimento, particularmente nas áreas de química fina e biotecnologia. A intensidade de P\&D das líderes equivale a $0,6 \%$ contra $0,3 \%$ das seguidoras, ainda que o percentual das líderes seja modesto em relação aos investimentos em P\&D realizados pelas matrizes dessas empresas no exterior. A sobrevivência das firmas seguidoras no longo prazo, porém, é incerta e dependente das estratégias das líderes tecnológicas e de mercado do setor, que envolveram fusões e aquisições a fim de aquisição de competências em biotecnologia e domínio do mercado de genéricos, que representa grande parcela do mercado brasileiro.

O processo de fusões e aquisições horizontais e verticais no Brasil refletiu tendências mundiais de incorporação de empresas com know-how em biotecnologia, especialmente manipulação genética de sementes para produção de novas variedades de plantas resistentes a classes de pesticidas específicos, de acordo com o interesse comercial das empresas. No caso brasileiro, há especial intenção de dominar técnicas de engenharia genética vinculadas a culturas com grande potencial de mercado mundial, como as de soja e cana-de-açúcar. Como reflexo dessas mudanças, houve significativo aumento de participação das quatro e oito principais líderes de mercado no período 1996-2006, que alcançou, respectivamente, $61 \%$ e $84 \%$ em 2006, em que pesem as expectativas de maior concorrência com a modificação do marco legal que introduziu o sistema de registro por equivalência, entre 2002 e 2006.

As perspectivas de concentração econômica do setor são elevadas, se consideradas as barreiras à entrada tradicionais do setor - procedimentos legais de registros de produtos e construção de redes de distribuição e de assistência técnica aos usuários - e o crescente conteúdo científico da 
atividade de $\mathrm{P} \& \mathrm{D}$, o que está associado às possibilidades de comandar o ritmo e direção das inovações. Nesse sentido, as grandes multinacionais do setor podem influenciar o grau de obsolescência tecnológica dos produtos existentes e produzir sementes transgênicas adaptadas às marcas de seus defensivos agrícolas, com o intuito de vender aos agricultores um pacote inteiro de produtos, da semente manipulada geneticamente ao pesticida que comercializa.

Os avanços tecnológicos recentes podem revolucionar a base tecnológica da agricultura tradicional e trazer sérias consequências em termos perda de competitividade, maior dependência tecnológica, desemprego ou mesmo insegurança alimentar, tendo em vista que grandes corporações internacionais investem e dominam tais técnicas. A fim de minimizar seus impactos socioeconômicos sobre a sociedade brasileira, seriam importantes medidas que combinassem incentivos fiscais, creditícios e financeiros para que empresas brasileiras que ainda atuam no segmento de agroquímicos internalizem capacidade de $\mathrm{P} \& \mathrm{D}$ e invistam em controle biológico de pragas ${ }^{17}$. A ausência de esforços internos de P\&D pode inviabilizar quaisquer possibilidades de entrada no setor abertas com mudanças de paradigmas. Essa recomendação equivale a uma tentativa de fazer a firma nacional migrar da categoria de seguidora para líder tecnológica do setor. Instituições de pesquisa brasileiras, como EMBRAPA e Centro Tecnologia Canavieira (CTC), entre outras, possuem know-how em biotecnologia que pode ser repassado a empresas nacionais que adquirirem capacidade mínima de $\mathrm{P} \& \mathrm{D}$.

Outras medidas seriam necessárias para estimular a produção nacional de defensivos para atenuar os problemas de déficit crescente da balança comercial do setor, além de estimular maior agregação de valor local. Para tal, poder-se-ia vincular, conforme sugestão de Velasco e Capanema (2006), a liberação de crédito agrícola do governo à compra de defensivos produzidos no Brasil. Nesse caso, as multinacionais que quisessem vender produtos importados aos agricultores teriam que financiá-los, ao invés do Governo. Essa medida poderia, inclusive, aumentar a oferta de crédito agrícola no Brasil.

${ }_{17}$ Conforme proposta do Projeto de Lei 2319/03 de Incentivo ao Controle Biológico (Fronzaglia, 2006). 


\section{Referências}

DE NEGRI, J. A., SALERMO, M. S. Inovações, padrões tecnológicos e desempenho das firmas industriais brasileiras. Brasilia, IPEA, 2005.

DE NEGRI, J. A., LEMOS, M. B., RUIZ, R. M., DE NEGRI, F. Empresas líderes na indústria brasileira: recursos, estratégias e inovação. Brasília, IPEA, 2007 (mimeo).

DULLEY, R.D. Nanotecnologia no agronegócio: explorando o futuro. São Paulo: Instituto de Economia Agrícola, 15 dez. 2004. Disponível em: <http://www.iea.sp.gov.br/out/ verTexto.php?codTexto=1640>. Acesso em 20 ago. 2009

FERMAM, R. K. S.; ANTUNES, A. Requisitos ambientais e acesso a mercados: o setor de defensivos agrícolas. Revista Brasileira de Política Internacional, v. 51, n. 2, 2008.

FERREIRA, C. R. R. P. T.; VEGRO, C. L. R. Fertilizantes: escalada das cotações e novo recorde nas vendas. Análises e indicadores do agronegócio. São Paulo, v.3, n.7, jul. 2008.

FRENKEL, J.; SILVEIRA, J. M. Tarifas, preços e a estrutura industrial dos insumos agrícolas: o caso dos defensivos. Brasília: IPEA, 1996 (Texto para discussão, 412)

FRONZAGlia, T. O futuro do controle biológico. Análises e Indicadores do Agronegócio; v.1, n.12, 07/12/2006. Disponível para download em: http://www.iea.sp.gov.br/out/verTexto.php?codTexto=8062

INSTITUTO INTERAMERICANO DE COOPERAÇÃO PARA AGRICULTURA (IICA). Situação e perspectivas da agricultura no Brasil 2006: inclui a linha do tempo. BRASÍLIA: IICA, 2007. 
KOShIYAMA, D. B.; MARTINS, M. Fusões e aquisições e concentração industrial na indústria brasileira de agroquímicos no período 1990-04. Ensaios FEE. v.29, n.01, 2008.

LEMOS, M. B. The agro-food system in semi-industrialized countries: the Brazilian case. Londres: University College London, 1992 (PhD Thesis).

MARTINELLI JÚNIOR, O. Relatório Setorial Final: Setor de Agroquímicos. Diretório de Pesquisa Privada/FINEP. 35p. São Paulo, 2005.

MARTINELLI JÚNIOR, O.; WAQUIL, P. D. Tendências recentes na indústria de defensivos agrícolas no Brasil. Análise Econômica. Porto Alegre, v.38, n.20, p.123-142, 2002.

MARTINS, P. R. Trajetórias tecnológicas e meio-ambiente: a indústria de agroquímicos/transgênicos no Brasil. Campinas: UNICAMP, 2000 (Tese de Doutorado).

PAVITT, K. Sectoral patterns of technical change: towards a taxonomy and a theory. Research Policy, v. 13, p. 343-373, 1984.

POSSAS, M. Estruturas de mercado em oligopólio. São Paulo: Hucitec, 1985.

TERRA, F. H. B. A indústria de agrotóxicos no Brasil. Curitiba: UFPR, 2008 (Dissertação de Mestrado).

VELASCO, L. O. M.; CAPANEMA, L. X. L. O setor de agroquímicos. BNDES Setorial. Rio de Janeiro, v.1, n.24, p.69-96, set. 2006. 
REVISTA DE ECONOMIA E AGRONEGÓCIO, VOL.9, $N^{o} 1$ 